\title{
Study of Tobacco Smoke and Pregnancy Outcome
}

\author{
Haerani Harun', Anwar Daud 2 , Veni Hadju³ ${ }^{3}$ Ridwan Amiruddin ${ }^{4}$, Anwar Mallongi², Rosmala Nur ${ }^{5}$ \\ ${ }^{1}$ Student of Doctoral Program, Faculty of Public Health Hasanuddin University, Makassar, Indonesia, ${ }^{2}$ Professor, \\ Department of Environmental Health, Faculty of Public Health Hasanuddin University, Makassar, Indonesia, \\ ${ }^{3}$ Professor, Department of Nutritional Sciences, Faculty of Public Health Hasanuddin University, Makassar, \\ Indonesia, ${ }^{4}$ Professor, Department of Epidemiology, Faculty of Public Health Hasanuddin University, Makassar, \\ Indonesia, ${ }^{5}$ Faculty of Public Health, Tadulako University, Palu, Indonesia
}

\begin{abstract}
Introduction. Pregnant women have a risk for tobacco smoke both actively and passively. Pregnant women are usually exposed to enviromental tobacco smoke (ETS) in various places with different duration of time. Cigarette smoke has a severe effect not only on pregnant women but also on the fetus.Methods Various references were collected from online database including reports, journals, mostly in the last 10 years. The journals were mostly from the scholarly journals.

Results. Tobacco smoke can effect the immunity, hormonal and metabolic system of the pregnant woman, therefore disturbing the growth of the fetus. Tobacco smoke also known to increase the risk of premature birth and reduce gestational age. Tobacco smoke cause several problems in newborn such as respiration distress, low birth weight (LBW), neural disorder, sudden infant death syndrome (SIDS) and congenital anomaly.
\end{abstract}

Conclusion. The effect of tobacco smoke, actively of passively, have worse outcome for the pregnant women and their babies.

Keyword: Pregnancy Outcome, tobacco smoke, ETS, LBW, preterm birth.

\section{Introduction}

Smoking pregnant women have an increased risk of having an ectopic pregnancy, spontaneous abortion and other complications leading to pregnancy complications as well as the placenta. The fetus also has the risk of exposure to tobacco smoke, more than thousands of types of hazardous chemicals, especially nicotine, tar and carbon monoxide can have an effect on the fetus and cause unwanted disorders or abnormalities ${ }^{1}$.

Environmental tobacco smoke (ETS) is a complex mixture consisting of most of the smoke emitted from the smoker's body, the smoke produced by burning cigarettes and the surrounding air $^{2}$. Exposure of ETS

\section{Corresponding author: \\ Haerani Harun \\ Presenting author: +6285242010535, \\ haeraniharun.unhas@gmail.com}

in pregnant women causes increased levels of carbon monoxyde $(\mathrm{CO})$, nicotine and cotinin in maternal serum or urine, in the fetus and in amniotic fluid. The effect of ETS on pregnant women can occur from the first semester to the third semester. Pregnant women are usually exposed to ETS in various places with different duration of time. Places that have the potential to become ETS exposure locations include at home, at work and the outside environment ${ }^{3}$.

Tobacco smoke and pregnancy

One effect of the cigarette smoke exposure on pregnant women is its effect on the mother's immune system. In pregnancy changes occur in the mother's immune system to prevent rejection of the fetus. Exposure to ETS can cause changes in the immune system of pregnant women. Changes include an increase in activated leukocytes and a decrease in the percentage of regulator T lymphocyte cells (Treg cells). Smoking 
during pregnancy also affects the function balance between Th1 cells ( $\mathrm{T}$ helper lymphocytes) and Th2 cells, causing an increase in the production of cytokines, proinflammatory chemokines and Th1 growth factors. In addition, the percentage of macrophages and NK cell residues is higher in smokers in the first semester

The activation of nicotine receptors causes the release of acetylcholine, dopamine, serotonin, growth hormones and adrenocorticotropic hormones and glutamate, these hormones significantly influence fetal growth. Smoking is also associated with changes in metabolism during pregnancy. ${ }^{4}$

Exposure to nicotine in pregnant women can cause vascular placental vasoconstriction, decrease placental blood flow and reduce trophoblast invasion which results in inhibition of good placental circularization leading to placental hypoxia causes disruption of placental invasion. Placenta previa is a form of placental invasion disorder ${ }^{4}$. Nicotine can cause a significant decrease in the mitotic potential of cytotrophoblast tissue in vitro. This effect is also found in smoker women. This effect can explain the mechanism of impaired placental development during the early phases of pregnancy due to placental ischemia which can cause fetal death ${ }^{5}$. Low placental weight strongly related with $\mathrm{LBW}^{6}$.

Beside nicotine and cotinin, $\mathrm{CO}$ levels are also the found highest in smokers. The presence of $\mathrm{CO}$ in the body causes oxygen binding to hemoglobin decrease due to the higher affinity of hemoglobin for CO. CO Exposure to the fetus prevents the release of oxygen and then converted to carboxyhemoglobin. The result is a decrease in tissue oxygenation through competitive inhibition with oxyhemoglobin. Prolonged CO exposure in pregnant women can cause significant permanent damage to the brain of a fetus which sensitive to hypoxia. Nicotine is also considered to have a bad effect due to the stimulation of nicotine cholinergic receptors and their neuroteratogenicity effects. ${ }^{4,7}$ Nicotine also interferes with the micro RNA which is important for the maturation of fetal stem cells. ${ }^{9}$

The effects of tobacco smok on the fetus are considered to be multifactorial, including indirect effects such as poor nutritional status associated with anorexiagenic effects of nicotine exposure, and CO. Placental blood flow decrease is associated with the vasoconstrictive effect of catecholamines released from adrenals and nerve cells after nicotine exposure. ${ }^{10}$

\section{Tobacco Smoke and Preterm Birth}

In Europe rates of preterm births are reported between $5-9 \%$, while in developing countries and the United States the rate of preterm births reaches $12 \%$. The cause of preterm birth is often difficult to determine. Some risk factors associated with preterm birth include excessive distension of the uterus, low economic status and smoking ${ }^{11}$. Elective preterm birth may be associated with cigarette-related obstetric complications such as placenta previa, placental abruption and impaired fetal growth. Research shows that smoking during pregnancy increases the risk of preterm birth by $25 \%$. The exposure of ETS also specifically has an influence on preterm birth $^{12,13}$.

Active smoker mothers have been accepted as a risk for preterm birth, for around $14 \%$ of preterm births. One mechanism that links cigarette exposure with preterm birth is the CYP1A1 genotype and GST (glutathione S-transferase). Abnormalities in these genes make mothers more vulnerable to exposure to hazardous substances such as cigarette smoke. ${ }^{14}$ Cotinin levels as an indicator of cigarette exposure are also strongly related to preterm birth ${ }^{4}$ The danger of non-smoking tobacco is also seen in the research of Munmun et al. Which shows that non-smoking tobacco (chewed and swallowed) increases the risk of preterm birth. ${ }^{15}$

There are four mechanisms proposed by Goldstein et al explain relationship between smoking and preterm birth: (a) Decreased maternal appetite caused by smoking leading to a decrease in nutrition for the fetus, (b) vasoconstriction caused by smoking results in decreased blood supply to the fetus, reduced fetal nutritional supply and slowing the release of catabolism results, (c) cigarettes may have a direct effect of toxins on the fetus and (d) increase in fetal CO levels causes reduced oxygen transport capacity and teratogenic properties. ${ }^{11,16}$

Prostagladin has been known to trigger labor. Prostaglandin levels such as F2-isoprostane as a marker of oxidative stress are found in the amniotic membrane and amniotic fluid in smokers. F2-isoprostane levels increased 3 times compared to non-smokers. Increased 
F2-isoprostane levels is considered as a mechanism that associated smoking and preterm birth. Smoking is also considered to increase the sensitivity of the uterus to contractile hormone. Research by Egawa et al in mice shows that inhalation of cigarette smoke increases the contractile activity and sensitivity of myometrium to oxytosis. ${ }^{11,17}$ Cadmium found in tobacco smoke interacts with calcium and effects myometrial activity. Cadmium may modulate the function of the oxytocin receptors in the myometrium. Increased levels of cadmium in pregnant women are found to be associated with an increased risk of preterm birth. ${ }^{11,18}$ Another condition associated with preterm birth is necrotizing-enterocolitis $(\mathrm{NEC})^{19}$

\section{Spontanious Abortion}

Spontaneous abortion or miscarriage is one of the most common pregnancy complications, about 12$26 \%$ of known pregnancies. Generally the literature on the relationship between smoking and abortion does not show any consistency although some studies have concluded that smoking can cause abortion. A metaanalysis study by Pineles et al. Showed the relative risk of abortion during pregnancy is 1.32 . The risk of abortion increases with the number of cigarettes. One cigarette per day increases the risk of abortion by $1 \%$. Secondary smokers have an $11 \%$ increased risk of abortion. ${ }^{20}$

\section{Tobacco Smoke Effect on Newborn}

Various studies provide an overview of the effects of cigarette smoke on fetal growth and development during pregnancy and infant growth and development after birth

\section{Respiratory Disorder}

Smoking during pregnancy can cause the newborn's lungs failed to reach maximum function and continues with decreased lung function. Preterm births in most smokers also cause disruption of lung maturation. Diseases caused by these infants include wheezing, bronchitis, hospitalization due to lung infections and asthma in children. ${ }^{21}$

Generally, children who are exposed to nicotine during pregnancy also experience exposure to cigarette smoke in childhood. This raises the question whether the increased risk of asthma is caused by exposure to prenatal or post natal cigarette smoke. Research by Pattenden et al showed that exposure to cigarette smoke during pregnancy without post natal exposure still shows an association with an increased risk of asthma. ${ }^{22,23}$ Exposure to cigarette smoke pre natal and post natal also shows an imbalance of Th1/Th2 causes susceptibility of airway reactivation. ${ }^{24}$

The mechanism of exposure to nicotine causes various pathological conditions in the lungs is not yet fully understood, but based on some data it was found that nicotine causes various anomalies in the lungs. Histological studies in animals show goblet cell hypertrophy after nicotine exposure, and it is associated with asthma in the community. ${ }^{22,25,26}$

\section{Low Birth Weight}

Low birth weight babies are the variables most widely studied the effect of smoking mothers during pregnancy or exposure to cigarette smoke in pregnant women on pregnancy outcomes. Data shows that LBW is more common in smokers $(12.4 \%)$ compared to nonsmokers $(7.7 \%)$. Women who smoke have a 1.5 to 3.5 times greater risk of giving birth to LBW, and the risk increases along with the cigarette consumption. ${ }^{1}$

Lee et al study showed that exposure to ETS in pregnant women also has the potential to cause LBW, and the effect of smoking on LBW from active smokers has the same mechanism as the effect of smoking on LBW in secondary smokers. The risk of small infants according to pregnancy is also increased in the group of mothers with high ETS exposure compared with mothers with low ETS exposure 27

\section{Behaviour and Neural Disorder}

Nicotine exposure to the fetus can affect fetal brain development ${ }^{10}$. A study in Finland shows that heavy nicotine exposure caused the infant born with attention deficit / hyperactivity disorder (AHDH) or attention deficit / hyperactive disorders. ${ }^{28}$ Fetuses exposed to tobacco smoke during pregnancy ware found to have a risk of cardiac autonomic abnormalities during sleep especially in preterm babies. Changes in autonomic activity are at risk of causing neurological and cardiological complications ${ }^{29}$.

\section{Sudden infant death syndrome (SIDS)}


One of the most severe complications of nicotine exposure in pregnancy is sudden infant death syndrome or SIDS. The cause of SIDS is not clearly known in infants less than one year old suddenly die without definite explanation even after a thorough investigation. Exposure to nicotine is known to be a risk factor for SIDS, but the mechanism of nicotine exposure that causes infant death is unclear and is still being debated. But some animal studies provide some clues. ${ }^{22,30,31}$

\section{Congenital Anomaly}

The effects of tobacco smoke on infanst congenital anomalies have been investigated. Exposure to tobacco smoke is known to be associated with fetal heart defects including atrial septal defects, atrioventricular septal defects, transposition of large arteries, craniosynostotic cleft palate and gastroschisis. ${ }^{4,33 .}$

\section{Conclusion}

Tobacco smoke effect the immunity, hormonal and metabolic system in pregnant women. The substance found in tobacco smoke were found to be the cause of some pregnancy complication leading to poor pregnancy outcome such as preterm birth, spontaneous abortion, and adverse effect on tha infants. The infants could suffer respiratory disorder, behavior and neural disorder, SIDS and another congenital anomaly.The effect of tobacco smoke, actively of passively, associated with poor outcome for the pregnant women and their babies.

Ethical Clearance- Taken from University ethical committee

\section{Source of Funding- Self}

Conflict of Interest - Nil

\section{References}

1. Setiati S, Laksmi PW. Peran Internis dalam tata laksana penyakit-penyakit pada kehamilan. PIPInterma; 2019.

2. Torres S, Merino C, Paton B, Correig X, Ramírez N. Biomarkers of Exposure to Secondhand and Thirdhand Tobacco Smoke: Recent Advances and Future Perspectives. International Journal of Environmental Research and Public Health. 2018 Nov 29;15(12):2693.

3. Abu-Baker N, Haddad L, Savage C. The Influence of Secondhand Smoke Exposure on Birth Outcomes in Jordan. International Journal of Environmental Research and Public Health. 2010 Feb 22;7(2):61634.

4. Sabra S, Gratacós E, Gómez Roig MD. SmokingInduced Changes in the Maternal Immune, Endocrine, and Metabolic Pathways and Their Impact on Fetal Growth: A Topical Review. Fetal Diagn Ther. 2017;41(4):241-50.

5. Qiu J, He X, Cui H, Zhang C, Zhang H, Dang Y, et al. Passive Smoking and Preterm Birth in Urban China. Am J Epidemiol. 2014 Jul 1;180(1):94-102.

6. Amiruddin R, Yusuf I. Influence of antenatal care, placental weight and genetic variation on low birth weight, Makassar Indonesia. Asia Pac J Public Health. 2008 Oct;20 Suppl:15-7.

7. Khader YS, Al-Akour N, AlZubi IM, Lataifeh I. The Association Between Second Hand Smoke and Low Birth Weight and Preterm Delivery. Matern Child Health J. 2011 May 1;15(4):453-9.

8. Goel P, Radotra A, Singh I, Aggarwal A, Dua D. Effects of passive smoking on outcome in pregnancy. Journal of Postgraduate Medicine. 2004 Jan 1;50(1):12.

9. Balaraman S, Winzer-Serhan UH, Miranda RC. Opposing Actions of Ethanol and Nicotine on MicroRNAs are Mediated by Nicotinic Acetylcholine Receptors in Fetal Cerebral CorticalDerived Neural Progenitor Cells. Alcoholism: Clinical and Experimental Research. 2012 Oct 1;36(10):1669-77.

10. Wickstrom R. Effects of Nicotine During Pregnancy: Human and Experimental Evidence [Internet]. 2007 [cited 2019 Mar 20]. Available from: https://www.ingentaconnect.com/content/ ben/cn/2007/00000005/00000003/art00009

11. Ion R, Bernal AL. Smoking and Preterm Birth. Reprod Sci. 2015 Aug 1;22(8):918-26.

12. Hayes C, Kearney M, O'Carroll H, Zgaga L, Geary M, Kelleher C. Patterns of Smoking Behaviour in Low-Income Pregnant Women: A Cohort Study of Differential Effects on Infant Birth Weight. International Journal of Environmental Research and Public Health. 2016 Oct 29;13(11):1060.

13. Elkin ER, O'Neill MS. Trends in Environmental Tobacco Smoke (ETS) Exposure and Preterm Birth: Use of Smoking Bans and Direct ETS Exposure Assessments in Study Designs. Chem Res Toxicol. 
2017 Jul 17;30(7):1376-83.

14. Luo Y-J, Wen X-Z, Ding P, He Y-H, Xie C-B, Liu T, et al. Interaction between Maternal Passive Smoking during Pregnancy and CYP1A1 and GSTs Polymorphisms on Spontaneous Preterm Delivery. PLOS ONE. 13 Nov 12;7(11):e49155.

15. Munmun FR, Rahman ME, Jahangir AF, Patwary MSA, Chowdhury AS, Kamruzzaman M. Role of Maternal Smokeless Tobacco Ingestion During Pregnancy in Delivery of Preterm Babies. 1. 2016;40(3):135-8.

16. Goldstein H, Goldberg ID, Frazier TM, Davis GE. Cigarette smoking and prematurity. Public Health Rep. 1964 Jul;79(7):553-60.

17. Egawa M, Yasuda K, Nakajima T, Okada H, Yoshimura T, Yuri T, et al. Smoking Enhances Oxytocin-Induced Rhythmic Myometrial Contraction. Biol Reprod. 2003 Jun 1;68(6):227480.

18. Nishijo M, Nakagawa $H$, Honda R, Tanebe K, Saito $\mathrm{S}$, Teranishi H, et al. Effects of maternal exposure to cadmium on pregnancy outcome and breast milk. Occupational and Environmental Medicine. 2002 Jun 1;59(6):394-7.

19. Ding G, Yu J, Chen Y, Vinturache A, Pang Y, Zhang J. Maternal Smoking during Pregnancy and Necrotizing Enterocolitis-associated Infant Mortality in Preterm Babies. Scientific Reports [Internet]. 2017 Dec [cited 2019 Mar 26];7(1). Available from: http://www.nature.com/articles/ srep45784

20. Pineles BL, Park E, Samet JM. Systematic Review and Meta-Analysis of Miscarriage and Maternal Exposure to Tobacco Smoke During Pregnancy. Am J Epidemiol. 2014 Apr 1;179(7):807-23.

21. Spindel ER, McEvoy CT. The Role of Nicotine in the Effects of Maternal Smoking during Pregnancy on Lung Development and Childhood Respiratory Disease. Implications for Dangers of E-Cigarettes. American Journal of Respiratory and Critical Care Medicine. 2016 Mar;193(5):486-94.

22. Holbrook BD. The effects of nicotine on human fetal development. Birth Defects Research Part C: Embryo Today: Reviews. 2016;108(2):181-92.

23. Pattenden S. Parental smoking and children's respiratory health: independent effects of prenatal and postnatal exposure. Tobacco Control. 2006 Aug 1;15(4):294-301.
24. Gibbs K, Collaco JM, McGrath-Morrow SA. Impact of Tobacco Smoke and Nicotine Exposure on Lung Development. Chest. 2016 Feb;149(2):552-61.

25. Blacquière $\mathrm{MJ}$, Timens $\mathrm{W}$, Melgert $\mathrm{BN}$, Geerlings M, Postma DS, Hylkema MN. Maternal smoking during pregnancy induces airway remodelling in mice offspring. European Respiratory Journal. 2009 May 1;33(5):1133-40.

26. Fahy JV. Remodeling of the Airway Epithelium in Asthma. Am J Respir Crit Care Med. 2001 Nov 15;164(supplement_2):S46-51.

27. Lee J, Lee D-R, Lee D-H, Paek Y-J, Lee W-C. Influence of Maternal Environmental Tobacco Smoke Exposure Assessed by Hair Nicotine Levels on Birth Weight. Asian Pacific Journal of Cancer Prevention. 2015 Apr 14;16(7):3029-34.

28. Sourander A, Sucksdorff M, Chudal R, Surcel HM, Hinkka-Yli-Salomäki S, Gyllenberg D, et al. Prenatal Cotinine Levels and ADHD Among Offspring. Pediatrics [Internet]. 2019 Mar [cited 2019 Mar 20];143(3). Available from: http:// europepmc.org/abstract/med/30804074

29. Stéphan-Blanchard E, Chardon K, Djeddi D-D, Léké A, Delanaud S, Bach V, et al. The dynamics of cardiac autonomic control in sleeping preterm neonates exposed in utero to smoking. Clinical Neurophysiology. 2016 Aug;127(8):2871-7.

30. Abbott LC, Winzer-Serhan UH. Smoking during pregnancy: lessons learned from epidemiological studies and experimental studies using animal models. Critical Reviews in Toxicology. 2012 Apr;42(4):279-303.

31. Adgent MA. Environmental tobacco smoke and sudden infant death syndrome: a review. Birth Defects Research Part B: Developmental and Reproductive Toxicology. 2006;77(1):69-85.

32. Cohen G, Roux J-C, Lagercrantz H. Perinatal exposure to nicotine causes deficits associated with a loss of nicotinic receptor function. :5.

33. Hackshaw A, Rodeck C, Boniface S. Maternal smoking in pregnancy and birth defects: a systematic review based on 173687 malformed cases and 11.7 million controls. Hum Reprod Update. 2011 Sep 1;17(5):589-604. 